\title{
Selection of optimal parameters of horizontal wells with SAGD technology based on numerical simulation
}

\author{
Evgeniy Shchesnyak ${ }^{1}$, Anatoliy Ryzhkov ${ }^{1}$, Iosif Ledovich $^{1}$, Andrey Osipov ${ }^{1, *}$, \\ and Artur Musin ${ }^{2}$ \\ 'People's Friendship University of Russia (RUDN University), 6 Miklukho-Maklaya Street, \\ Moscow, 117198, Russian Federation \\ ${ }^{2}$ VNIIneft JSC, 10 Dmitrovskiy Proezd, Moscow, 127422, Russian Federation
}

\begin{abstract}
As the development of reserves of traditional oil takes place, an important component of the raw material base is the reserves of highly viscous oil and natural bitumen, one of the effective methods for the development of which is the SAGD technology. This paper is devoted to optimizing the length of the horizontal section of wells with the SAGD technology using numerical modeling for one of the fields of high-viscosity Caribbean oil and finding the analytical dependence of the technological characteristics of the method on the parameters of the wells. The solution of the tasks was carried out using a thermohydrodynamic simulator «CMG STARS» (Computer Modeling Group). The paper presents the results of calculations to determine the optimal rate of steam injection and the length of a horizontal wellbore at the SAGD, as well as the analytical dependence of the technological characteristics of the parameters of the well, which can be used for an initial assessment of the effectiveness of technology for specific geological and physical conditions in this area.
\end{abstract}

\section{Introduction}

The most important component of the raw material base of the oil industry of the countries of the world are stocks of heavy and bituminous oils. The IEA estimates that there are 6 trillion barrels of heavy oil worldwide, with 2 trillion barrels ultimately recoverable $[1,2]$. Western Canada is estimated to hold 2.5 trillion barrels, Venezuela - 1.5 trillion barrels, Russia - more than 1 trillion barrels, United States - 180 billion barrels.

Heavy oil is also located - and being produced - in Indonesia, China, Mexico, Brazil, Trinidad, Argentina, Ecuador, Colombia, Oman, Kuwait, Egypt, Saudi Arabia, Turkey, Australia, India, Nigeria, Angola, Eastern Europe, the North Sea, Iran, and Italy [3].

The problem of involvement in the active development of high-viscosity oil fields is becoming increasingly urgent from year to year.

\footnotetext{
* Corresponding author: aosipov@ vniineft.ru
} 
Thermal methods of enhanced oil recovery currently have no alternative in the development of high-viscosity oil fields. The most common among thermal methods are steam thermal methods of influence, in particular, steam and gravity drainage of the reservoir or SAGD (steam-assisted gravity drainage) - the main method of extracting natural bitumen. This technology [4-6] uses two horizontal wells, which are drilled in parallel near the bottom of the formation at a distance of 5-10 m one above the other (Fig. 1). The upper well is designed to inject steam and create a high-temperature steam chamber in the reservoir, the lower one - for oil production. Currently, the SAGD method is widely used in the fields of superviscous oils in Canada, the USA, Venezuela, and China. In Russia, using this method, mining is carried out at the Ashalchinsky field in the Republic of Tatarstan [7], on the Lyaelskaya area of the Yaregsky field [8] and at the Usinsk field in the Komi Republic [9].

Experimental studies on the physical model and numerical calculations on the hydrodynamic simulator CMG STARS showed that there are three main stages of the process. At the initial stage, steam having a relatively low density rises and the steam chamber grows to the top of the seam. After that, it continues to expand in the horizontal direction. In its form, the steam chamber in a plane perpendicular to the wells, is close to a triangle, whose apex coincides with the producing well (Fig. 2). At the final stage, the steam chamber expands in the direction of the bottom of the formation (Fig. 3). When developing deposits of super-viscous oil according to the standard SAGD technology, rows of pairs of injection-producing wells are used. Steam chambers are formed over each pair of wells and, reaching the top of the reservoir, spread in a horizontal plane until they close. In fig. 4 shows the development stages of the steam chamber in an experiment on a physical model [10].

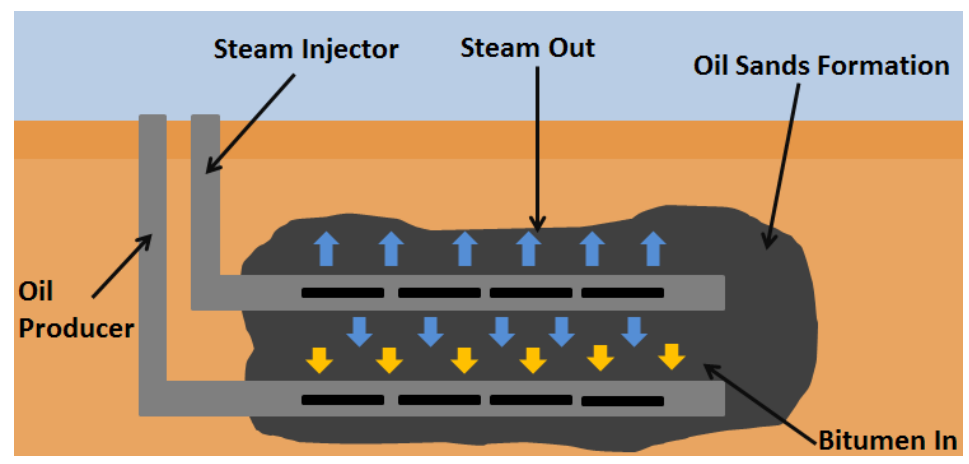

Fig. 1. Scheme of development of high-viscosity oil fields by the system of horizontal wells using the SAGD technology.

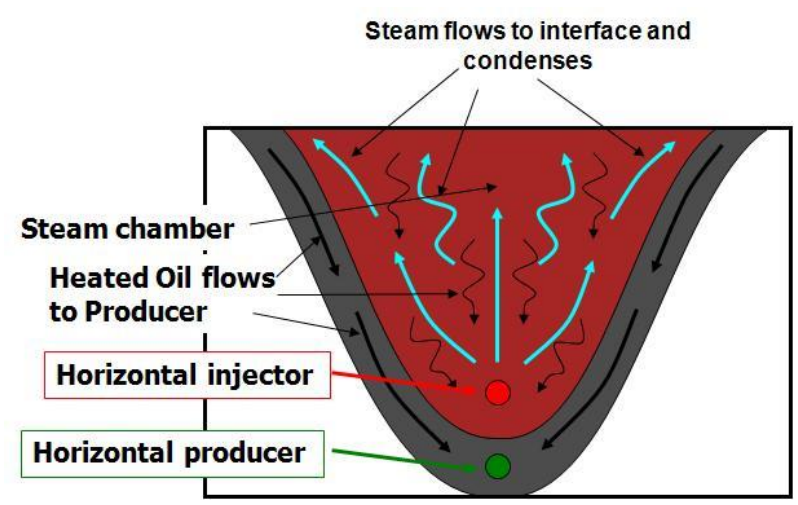

Fig. 2. Steam chamber in section (schematic image). 


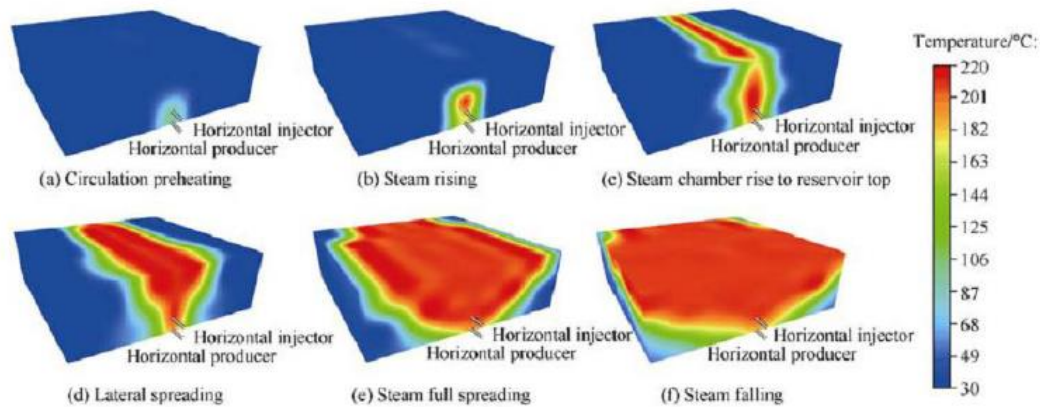

Fig. 3. Steps for the development of a steam chamber (numerical simulation).

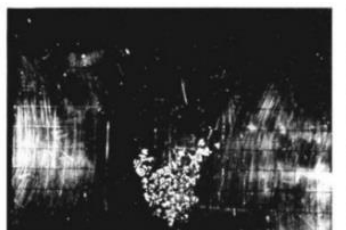

11 минут

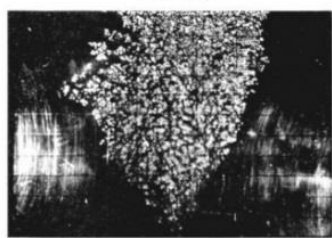

35 минут

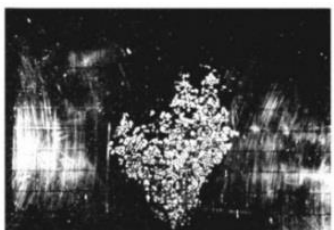

19 минут

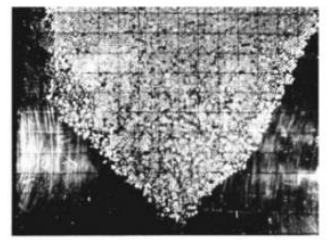

52 минуты

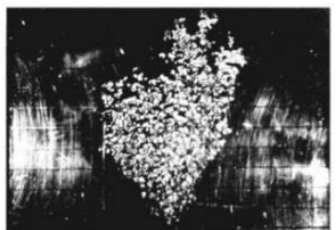

27 минут

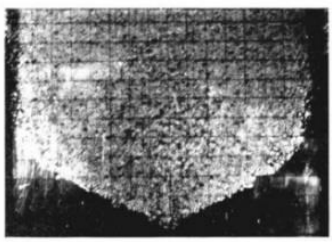

76 минут

Fig. 4. Physical Modeling SAGD.

The main capital cost of SAGD is the cost of the wells, and the main operating costs are the cost of generating steam [11]. Therefore, to achieve the maximum technological and economic efficiency of the method, it is necessary to optimize the well length and the volume of injected steam.

In this regard, in the present work the following tasks were solved:

- Determination of the optimal rate of steam injection for different lengths of a horizontal wellbore;

- Determination of the optimal length of a horizontal wellbore based on the criterion of maximum oil production;

- Determination of the approximate dependence of the cumulative oil production on the length of the horizontal wellbore and the steam injection rate.

\section{Modeling conditions}

The tasks were solved for one of the fields of natural bitums of the Caribbean, the main characteristics of which are presented in Table 1.

Hydrodynamic modeling was carried out on a sector model with geometrical dimensions of $1000 \times 100 \times 86 \mathrm{~m}(\mathrm{X} * \mathrm{Y} * \mathrm{Z})$ in the thermal simulator "CMG STARS" (Computer Modeling Group). The number of cells in the sector model was: along the $X$ axis -20 , along the $\mathrm{Y}$ axis -40 , along the $\mathrm{Z}$ axis -110 . Typical dimensions of the cells: along the axis of the wells $-50 \mathrm{~m}$, perpendicular to the axis of the wells $-2.5 \mathrm{~m}$, on the vertical $-0.8 \mathrm{~m}$. 
At the initial moment of time, the fields of distribution of pressure and fluid saturations should ensure the static equilibrium of the model. Achieving such a state is possible using the option of gravitational-capillary equilibrium, present in all modern simulators.

The initial distribution of oil saturation of the reservoir was calculated according to the data of the digital geological model. The initial pressure distribution was constructed as a function of depth and saturation according to the known initial reservoir pressure at a certain absolute depth of the development object.

The dependence of oil viscosity on temperature, used in the model, is shown in Figure 5.

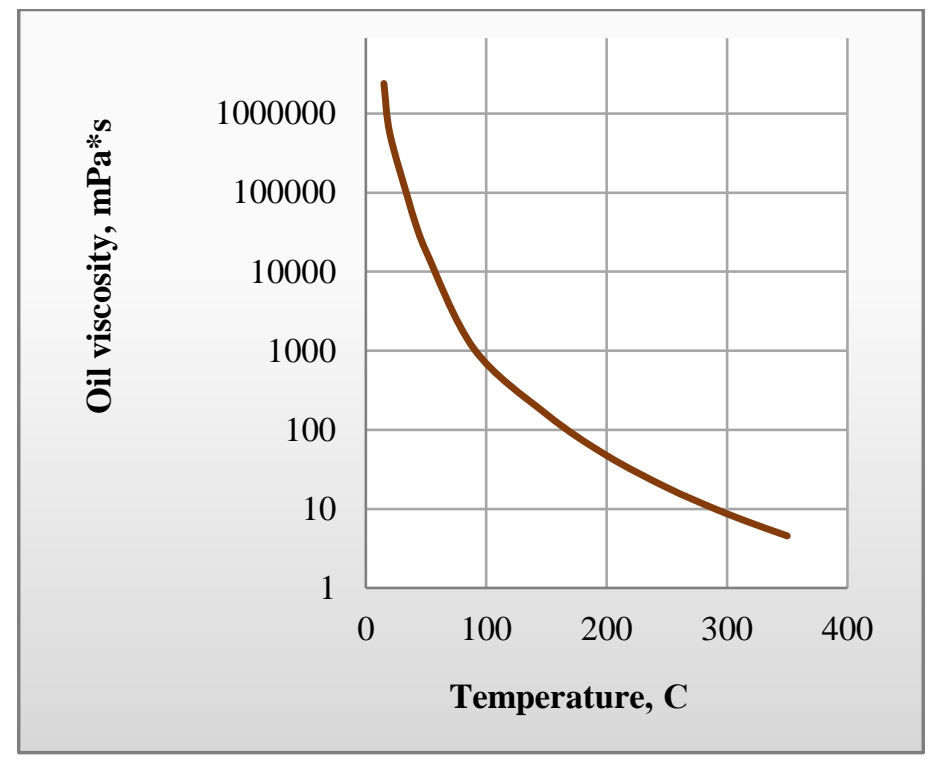

Fig. 5. Dependence of viscosity of degassed oil on temperature.

The work of one pair of SAGD wells with different lengths of a horizontal wellbore section was modeled.

The operating parameters of the injection well were as follows:

- $\quad$ Steam injection pressure - 8.5 MPa;

- Injected steam temperature $-300^{\circ} \mathrm{C}$;

- $\quad$ Degree of steam dryness - 0.75 .

- The operating parameters of the production well were as follows:

- Minimum bottomhole pressure - 5.5 MPa;

- Maximum liquid flow rate $-500 \mathrm{~m}^{3} /$ day.

The work of the wells in the model was stopped when the current steam-oil factor (PNF) reached the value of the maximum economically viable level -12 tons of steam $/ \mathrm{m}^{3}$ of oil.

Since natural bitumens in reservoir conditions are practically immobile, in order to create an initial hydrodynamic connection between a pair of SAGD wells, in practice, the interwell zone is heated by circulating the pair simultaneously in the production and injection wells. In the model, this period was 6 months. 


\section{The sequence of problem solving}

\subsection{Stage 1}

At the first, the optimal steam pumping rate was determined on the basis of multivariate calculations for various lengths of the horizontal section of the wellbore by the criterion of maximum oil production. The calculation results are presented in tables 2-5.

As we can see from the tables, the best values of steam injection rate for options with horizontal trunk lengths of $250 \mathrm{~m}, 500 \mathrm{~m}, 750 \mathrm{~m}$ and $1000 \mathrm{~m}$ are $450 \mathrm{~m}^{3} / \mathrm{day}, 500 \mathrm{~m}^{3} /$ day, $550 \mathrm{~m}^{3} /$ day and $600 \mathrm{~m}^{3} /$ days respectively.

Table 1. Basic geological and physical characteristics.

\begin{tabular}{|c|c|c|c|}
\hline No. & Significative & Units & Value \\
\hline 1 & Average depth & $\mathrm{m}$ & 600 \\
\hline 2 & Type of reservoir & & massive \\
\hline 3 & Type of collector & & Carbonate \\
\hline 4 & Average total thickness & $\mathrm{m}$ & 207 \\
\hline 5 & Average effective oil saturated thickness & $\mathrm{m}$ & 73 \\
\hline 6 & Porosity & unit fraction & 0.38 \\
\hline 7 & Oil saturation & unit fraction & 0.61 \\
\hline 8 & Permeability & $10^{-6} \mathrm{~m}^{2}$ & 869 \\
\hline 9 & Net to gross & unit fraction & 0.63 \\
\hline 10 & Average number of permeable intervals & unit fraction & 10 \\
\hline 11 & Initial reservoir temperature & ${ }^{\circ} \mathrm{C}$ & 36 \\
\hline 12 & Initial reservoir pressure & $\mathrm{MPa}$ & 6.16 \\
\hline 13 & Oil viscosity in reservoir conditions & $\mathrm{mPa} * \mathrm{~s}$ & 35552 \\
\hline 14 & Oil density in reservoir conditions & $\kappa \Gamma / \mathrm{M}^{3}$ & 1029 \\
\hline 15 & Oil density in surface conditions & $\kappa \Gamma / \mathrm{M}^{3}$ & 1021 \\
\hline 16 & Oil volume factor & unit fraction & 1.0095 \\
\hline 17 & Bubble point pressure & $\mathrm{MPa}$ & 1.95 \\
\hline 18 & Gas oil ratio & $\mathrm{m}^{3} / \mathrm{m}^{3}$ & 2.40 \\
\hline
\end{tabular}

Table 2. The results of the calculations (the length of the horizontal well $-250 \mathrm{~m}$ ).

\begin{tabular}{|c|c|c|c|}
\hline \multirow{2}{*}{ Steam rate, $\mathbf{~ m}^{\mathbf{3}} \mathbf{d} \mathbf{d a y}$} & \multirow{2}{*}{ Cumulative oil, $\mathbf{1 0}^{\mathbf{3}} \mathbf{~}^{\mathbf{3}}$} & \multicolumn{2}{|c|}{ Steam oil ratio, $\mathbf{t} / \mathbf{m}^{\mathbf{3}}$} \\
\cline { 3 - 4 } & & Current & Cumulative \\
\hline 200 & 278.5 & 11.9 & 6.4 \\
\hline 250 & 309.9 & 11.9 & 6.2 \\
\hline 300 & 335.9 & 11.7 & 6.3 \\
\hline 350 & 356.4 & 11.8 & 6.5 \\
\hline 400 & 371.3 & 11.2 & 6.7 \\
\hline 450 & 380.8 & 11.6 & 6.5 \\
\hline 500 & 378.0 & 11.4 & 6.6 \\
\hline 550 & 375.5 & 11.3 & 6.8 \\
\hline 600 & 370.5 & 11.8 & 6.9 \\
\hline 650 & 360.6 & 11.7 & 6.7 \\
\hline 700 & 345.6 & 11.8 & 7.0 \\
\hline 750 & 322.1 & 11.9 & 6.9 \\
\hline 800 & 293.1 & 11.4 & 7.1 \\
\hline 850 & 258.5 & 11.1 & 7.3 \\
\hline
\end{tabular}


Table 3. The results of the calculations (the length of the horizontal well $-500 \mathrm{~m}$ ).

\begin{tabular}{|c|c|c|c|}
\hline \multirow{2}{*}{ Steam rate, $\mathbf{~ m}^{\mathbf{3}} \mathbf{d}$ day } & \multirow{2}{*}{ Cumulative oil, $\mathbf{1 0}^{\mathbf{3}} \mathbf{~ m}^{\mathbf{3}}$} & \multicolumn{2}{|c|}{ Steam oil ratio, t/m } \\
\cline { 3 - 4 } & & Current & Cumulative \\
\hline 200 & 539.1 & 11.7 & 6.5 \\
\hline 250 & 579.8 & 11.5 & 6.6 \\
\hline 300 & 613.4 & 11.9 & 6.2 \\
\hline 350 & 640.0 & 11.7 & 6.0 \\
\hline 400 & 659.6 & 11.3 & 6.5 \\
\hline 450 & 672.2 & 11.2 & 6.8 \\
\hline 500 & 677.8 & 11.6 & 6.6 \\
\hline 550 & 676.4 & 11.7 & 6.7 \\
\hline 600 & 668.0 & 11.5 & 6.8 \\
\hline 650 & 652.6 & 11.9 & 6.7 \\
\hline 700 & 630.2 & 11.4 & 6.8 \\
\hline 750 & 600.8 & 11.2 & 6.9 \\
\hline 800 & 564.4 & 11.1 & 7.0 \\
\hline 850 & 521.0 & 11.3 & 7.1 \\
\hline
\end{tabular}

Table 4. The results of the calculations (the length of the horizontal well $-750 \mathrm{~m}$ ).

\begin{tabular}{|c|c|c|c|}
\hline \multirow{2}{*}{ Steam rate, $\mathbf{~ m}^{\mathbf{3}} / \mathbf{d a y}$} & \multirow{2}{*}{ Cumulative oil, $\mathbf{1 0}^{\mathbf{3}} \mathbf{m}^{\mathbf{3}}$} & \multicolumn{2}{|c|}{ Steam oil ratio, t/ $\mathbf{m}^{\mathbf{3}}$} \\
\cline { 3 - 4 } & & Current & Cumulative \\
\hline 250 & 711.1 & 11.6 & 7.0 \\
\hline 300 & 741.2 & 11.8 & 6.9 \\
\hline 350 & 770.2 & 11.7 & 6.9 \\
\hline 400 & 790.3 & 11.4 & 6.8 \\
\hline 450 & 804.7 & 11.2 & 6.7 \\
\hline 500 & 810.9 & 11.1 & 6.8 \\
\hline 550 & 820.3 & 11.8 & 6.6 \\
\hline 600 & 811.0 & 11.7 & 6.7 \\
\hline 650 & 794.8 & 11.6 & 6.9 \\
\hline 700 & 773.7 & 11.2 & 7.0 \\
\hline 750 & 745.7 & 11.4 & 7.2 \\
\hline 800 & 710.6 & 11.5 & 7.1 \\
\hline 850 & 668.6 & 11.9 & 7.3 \\
\hline 900 & 619.5 & 11.3 & 7.4 \\
\hline
\end{tabular}

Table 5. The results of the calculations (the length of the horizontal well $-1000 \mathrm{~m}$ ).

\begin{tabular}{|c|c|c|c|}
\hline \multirow{2}{*}{ Steam rate, $\mathbf{~ m}^{\mathbf{3}} / \mathbf{d a y}$} & \multirow{2}{*}{ Cumulative oil, $\mathbf{1 0}^{\mathbf{3}} \mathbf{~ m}^{\mathbf{3}}$} & \multicolumn{2}{|c|}{ Steam oil ratio, t/m $\mathbf{m}^{\mathbf{3}}$} \\
\cline { 3 - 4 } & & Current & Cumulative \\
\hline 250 & 568.5 & 11.4 & 7.6 \\
\hline 300 & 606.3 & 11.3 & 7.2 \\
\hline 350 & 637.2 & 11.1 & 7.1 \\
\hline 400 & 650.0 & 11.8 & 6.9 \\
\hline 450 & 664.1 & 11.9 & 6.7 \\
\hline 500 & 673.3 & 11.7 & 6.6 \\
\hline 550 & 680.5 & 11.4 & 6.5 \\
\hline 600 & 689.2 & 11.5 & 6.6 \\
\hline 650 & 675.3 & 11.6 & 6.8 \\
\hline 700 & 657.2 & 11.7 & 6.9 \\
\hline 750 & 632.1 & 11.2 & 7.1 \\
\hline 800 & 599.9 & 11.3 & 7.5 \\
\hline 850 & 560.8 & 11.7 & 7.3 \\
\hline
\end{tabular}




\begin{tabular}{|c|c|c|c|}
\hline \multirow{2}{*}{ Steam rate, $\mathbf{~ m}^{\mathbf{3}} / \mathbf{d a y}$} & \multirow{2}{*}{ Cumulative oil, $\mathbf{1 0}^{\mathbf{3}} \mathbf{m}^{\mathbf{3}}$} & \multicolumn{2}{|c|}{ Steam oil ratio, $\mathbf{t} / \mathbf{m}^{\mathbf{3}}$} \\
\cline { 3 - 4 } & 514.6 & Current & Cumulative \\
\hline 900 & \multicolumn{2}{|c}{11.4} & 7.5 \\
\hline
\end{tabular}

\subsection{Stage 2}

At the second stage the optimal value of the length of the horizontal wellbore was determined based on the criterion of maximum oil production. The results of the calculations are presented in table 6 and figure 6.

Based on the obtained results it can be concluded that the optimal value of the length of horizontal wells is $750 \mathrm{~m}$.

Table 6. The results of determining the optimal value of the length of horizontal wells

\begin{tabular}{|c|c|c|}
\hline Well length, $\mathbf{m}$ & Steam rate, $\mathbf{m}^{\mathbf{3}} /$ day & Cumulative oil, $\mathbf{1 0}^{\mathbf{3}} \mathbf{~ m}^{\mathbf{3}}$ \\
\hline 250 & 450 & 381 \\
\hline 500 & 500 & 678 \\
\hline 750 & 550 & 820 \\
\hline 1000 & 600 & 689 \\
\hline
\end{tabular}

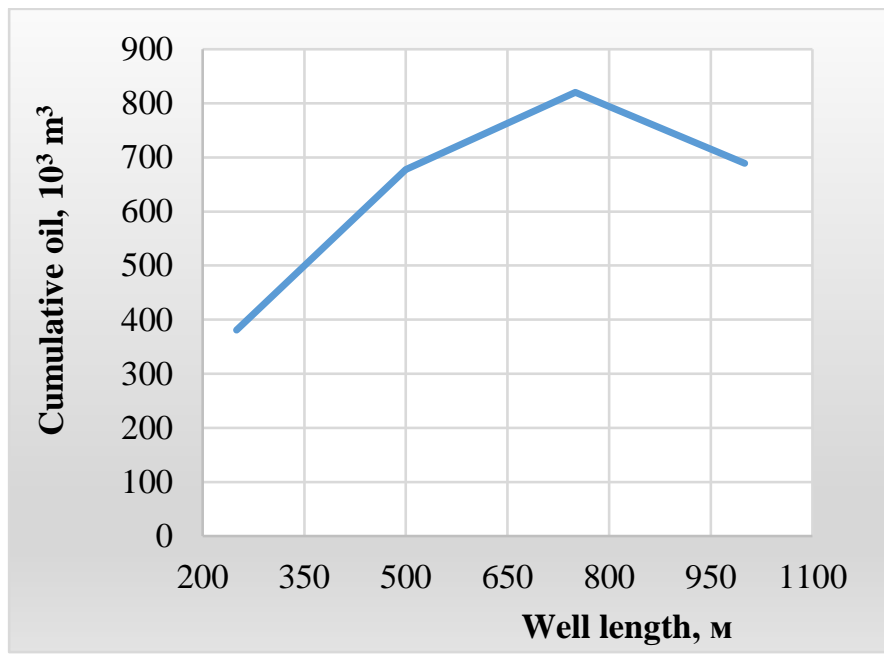

Fig. 6. Dependence of cumulative oil production on well length.

\subsection{Stage 3}

At the third stage we select the approximating dependence of the cumulative oil production on the length of the horizontal well and the rate of steam injection by the method of regression analysis. As a result, the following analytical dependence was obtained:

$Q o=-0.881 \cdot L^{3}+1.21 \cdot 10^{-3} \cdot L^{2}-1.5 \cdot 10^{-6} \cdot L-0.157 \cdot q^{3}+1.513 \cdot 10^{-3} \cdot q^{2}-1.6 \cdot 10^{-6} \cdot q$

$Q o$ - cumulative oil $\left(10^{3} \mathrm{~m}^{3}\right), L$ - well length $(\mathrm{m}), q$ - steam rate $\left(\mathrm{m}^{3} /\right.$ day).

The results of comparing the calculated values of cumulative oil production with the calculated by the formula data are presented in Fig. 7. The average difference in cumulative oil production is $2.5 \%$. 
According to the obtained analytical formula contour surfaces were constructed for the dependence of the cumulative oil production on the steam injection rate and the length of the horizontal well (Fig. 8).

Oval areas colored in different colors correspond to a definite range of changes in cumulative oil production depending on the steam injection rate and the length of the horizontal wellbore.

The resulting graphoanalytical dependence can be considered as the primary method for assessing the effectiveness of SAGD for specific geological and physical conditions of a given field.

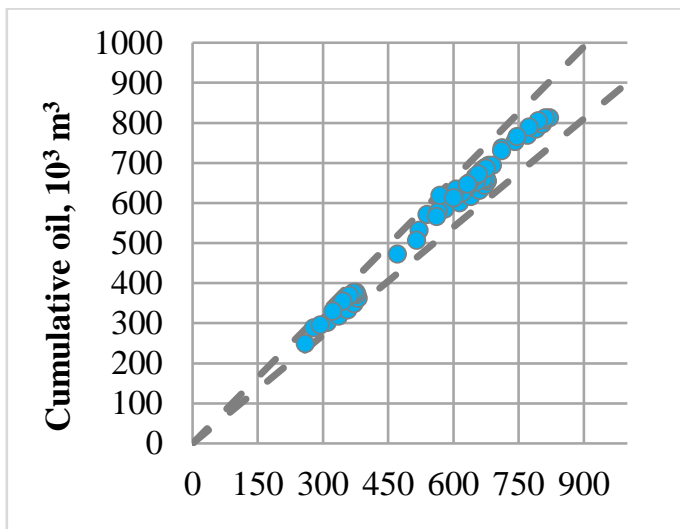

Cumulative oil (calculation), $10^{3} \mathrm{~m}^{3}$

Fig. 7. Cross-plot of cumulative oil production.

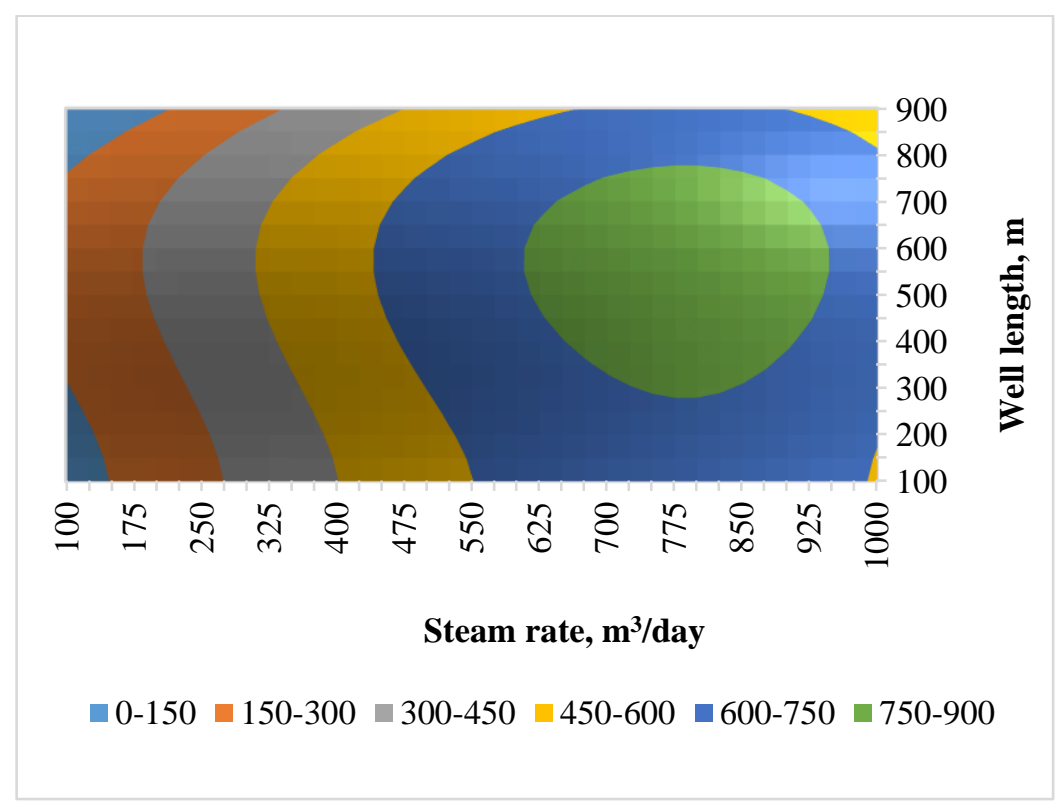

Fig. 8. Contour surface of cumulative oil production. 


\section{Results}

As a result of the research, the following results were obtained:

- $\quad$ The best values of the steam injection rate were determined depending on the length of the horizontal wellbore for the SAGD technology in specific geologo-physical conditions;

- $\quad$ The optimal value of the length of horizontal wells was determined on the basis of the maximum oil production criterion;

- An analytical dependence of the cumulative oil production on the length of the horizontal wellbore and steam injection rate was obtained, which can be used for the initial assessment of the effectiveness of the SAGD technology for specific geological - physical conditions of this field.

\section{References}

1. C. Besson, Resources to Reserves, Oil \& Gas Technologies for the Future (International Energy Agency, 2005)

2. Survey of Energy Resources, World Energy Council, Published by Elsevier Ltd. (2004)

3. Facing the Hard Truths about Energy - A Comprehensive View to 2030 of Global Oil and Natural Gas, National Petroleum Council, USA. http://www. npchardtruthsreport.org

4. R. Butler, Thermal recovery of oil and bitumen (New Jersey, Prentice Hall, 1991)

5. R. Butler, A Method for Continuously Producing Viscous Hydrocarbons by Gravity Drainage While Injecting Heated Fluids (UK Pat. App. GB 2,053,328 (1980), US 4,344,485 (1982), Can. 1,130,201 (1982)

6. R. Butler, H. Lo, The Canadian Journal of Chemical Engineering, 59 (1981)

7. R. Khisamov, A. Zaripov, D. Shaikhutdinov, Best Configuration of Horizontal and Vertical Wells for Heavy Oil Thermal Recovery from Thin Net Pay Zones (SPE Russian Petroleum Technology Conference, 26-28 October, 2015)

8. D. Loparev, Construction Method of Horizontal Steam-Injection and Producing Oil Wells on the Test Sections OPU-4 and OPU-5 Yarega Heavy Oil Deposit (SPE Russian Oil and Gas Technical Conference and Exhibition, 28-30 October, 2018)

9. S. Ursegov, E. Taraskin, A. Zakharian, Thermal Performance Challenges and Prospectives of the Russian Largest Carbonate Reservoir with Heavy Oil (SPE EOR Conference at Oil and Gas West Asia, 26-28 March, 2018)

10. R. Butler, D. Stephens, JCPT, 90-96 (1981)

11. N. Edmunds, H. Chhina, Journal of Canadian Petroleum Technology 40, 12 (2001) 